\title{
Bacterial and Viral Vaccination (non EPI) Coverage among Students in Three Educational Institutions in Bangladesh
}

\author{
Tanzila Rawnuck ${ }^{* 1}$, Md Selim Reza², Sabiha Monowar ${ }^{3}$
}

\begin{abstract}
Introduction: The implementation of the vaccine has already been shown to be a great success to reduce communicable diseases and its associated morbidity among human globally. The aim of this study was to figure out the actual rate of population who received non EPI bacterial and viral vaccines and to determine the risk factors associated with it. Materials and Methods: A retrospective observational study was conducted between September 2011 and August 2014 among 3600 students aged from 18 years to 24 years. Data of total 12 non EPI vaccines (5 bacterial - Cholera and ETEC diarrhea vaccine, Meningococcal, Pneumococcal, Tetanus and Typhoid; 7 viral-Chicken pox, Cervical vaccine, Hepatitis A, Hepatitis B, Measles Mumps Rubella vaccine, Rota viral and Seasonal flu vaccine) were collected from the individuals' vaccine cards. All vaccine timelines were categorized into timely, early, delayed and missed based on recommended time of vaccination. Different parameters were considered to determine the socio-demographic factors related to vaccination. Results: Total of 3600 study population were selected from three different institutes. Percentage of rural students was almost 3.2 times higher than that of urban. About 1746(48.5\%) student were from middle class family. About 2125(59.03\%) of the participant's had not adequate knowledge of vaccination. Out of 3600 study population for bacterial vaccine, rate of Tetanus vaccine was the highest in percentage which was 1248(34.67\%). Percentage of other bacterial vaccines such as Cholera and ETEC diarrhea, Meningococcal, Pneumococcal and Typhoid vaccination percentages were only 27(0.75\%), $29(0.81 \%), 111(3.08 \%)$ and $34(0.94 \%)$ respectively. Among viral vaccines, the highest receiving vaccine was Hepatitis $B$. $2763(76.75 \%)$ people were immune with hepatitis B vaccine. Percentage of Hepatitis A was 337(9.36\%), Rota viral vaccine was 330(9.17\%), Measles Mumps Rubella was 249(6.92\%) and Chicken pox was 83(2.31\%). The percentage was less in case of Cervical HPV and Seasonal flu vaccines which were $12(0.33 \%)$ and 20(0.56\%) respectively. Conclusion: Vaccines have proven the potential capability to reduce vaccine-preventable diseases, however, findings from the study show that people have still not been aware of non EPI bacterial and viral vaccines which can protect people from life threatening diseases and their complications.
\end{abstract}

Keywords: Bacterial vaccine coverage, Viral vaccine coverage, Non EPI vaccine.

Number of Tables: 02; Number of References: 21; Number of Correspondence: 05.

*1. Corresponding Author:

Dr. Tanzila Rawnuck

Assistant Professor

Department of Pathology with Microbiology

Dhaka Dental College, Dhaka, Bangladesh.

E-mail:drrawnuck@gmail.com

2. Dr. Md Selim Reza

Assistant Professor

National Institute of Traumatology \& Orthopaedic

Rehabilitation (NITOR), Dhaka, Bangladesh.

3. Dr. Sabiha Monowar

Assistant Professor

Department of Microbiology

MARKS Medical College, Dhaka, Bangladesh.

\section{Introduction:}

Immunization has become one of the major contributors to public health globally as it prevents communicable diseases among human ${ }^{1}$. Vaccines rarely provide full protection from disease. Nevertheless, Vaccines may be used to protect both individuals and whole populations $\mathbf{s}^{2,}{ }^{3}$. Vaccine contributes to the reduction of morbidity and mortality worldwide 4 . Despite the success rate of advanced vaccine approximately 1.5 million people die each year from vaccinepreventable diseases ${ }^{5}$. Vaccine-preventable diseases remain a potential public health problem in South-East Asia ${ }^{6}$ including Bangladesh for its early or delayed, incomplete, and low vaccination coverage ${ }^{7}$. The objective of this study was to estimate the extent of coverage of life saving non-EPI bacterial and viral vaccines among the students of three different institutes in its time schedule, and to investigate the factors of incomplete and failure of timely vaccination.

\section{Materials and Methods:}

A retrospective observational study was conducted between September 2011 and August 2014 which occured among 3600 students of three different government institutes; Rajshahi University (RU), Rajshahi Medical College (RMC) and Rajshahi University of Engineering and Technology (RUET). A sum of 2450 students was selected from different departments of RU, about 600 students were enrolled from RMC and 550 students from RUET were participated in this study. They were divided in male and female groups. Students aged 18-24 years with the availability of vaccine cards and willing to participate in this study were included. Students who had no available vaccine cards, age limits were not matched and was not willing to participate were excluded from the study. All vaccine timelines were categorized into timely, early, delayed and missed based on recommended time of vaccination. Timely vaccination was considered as receiving 
a particular vaccine within the recommended time, whereas early and delayed vaccination was defined as administration of vaccine early and after the recommended time respectively. Missed vaccination was considered as failure to administration of a particular dose. Data were collected based on the availability of the vaccine card. Data of total 12 non EPI vaccines (Five bacterial- Cholera and ETEC diarrhea vaccine, Meningococcal, Pneumococcal, Tetanus and Typhoid; Seven viral- Chicken pox, Cervical vaccine, Hepatitis A, Hepatitis B, Measles Mumps Rubella vaccine, Rota viral and Seasonal flu vaccine) were collected from the individuals' vaccine cards. Written consents were taken from the respondents during the interviews. Study was conducted from September 2011 to August 2014, and different parameters were considered to determine the socio-demographic factors related to vaccination. SPSS version 19 was used for data analysis.

\section{Results:}

Table I shows total 3600 study population was selected from three different institutes. Among them, 2450, 600 and 550 were from RU, RMC and RUET respectively. Percentage of male 1898 (52.72\%) was slightly higher than female 1702 (47.28\%). Percentage of rural population 2743 (76.19\%) was almost 3.2 times higher than urban population 857 (23.81\%). The proportion of uneducated, primary/secondary education and highly educated parents were 791 (21.97\%), 1571(43.64\%) and 1238 (34.39\%) respectively. Most of the study populations were from middle class family about 1746 (48.5\%). Most of the participant's $2125(59.03 \%)$ had not adequate knowledge about vaccine and its functions.

Table-I: Factors associated with rate of vaccination $(n=3600)$ :

\begin{tabular}{|c|c|c|c|c|c|}
\hline \multicolumn{2}{|c|}{ Related factors } & \multirow{2}{*}{$\begin{array}{c}\text { RU (2450) } \\
1221\end{array}$} & \multirow{2}{*}{$\begin{array}{c}\mathrm{RMC}(\mathbf{6 0 0 )} \\
184\end{array}$} & \multirow{2}{*}{$\begin{array}{c}\text { RUET (550) } \\
493\end{array}$} & \multirow{2}{*}{$\begin{array}{c}\begin{array}{c}\text { Total number \& } \\
\text { percentage } \%\end{array} \\
1898(52.72 \%)\end{array}$} \\
\hline Ser & Male & & & & \\
\hline Sex & Female & 1229 & 416 & 57 & $1702(47.28 \%)$ \\
\hline \multirow{2}{*}{ Place of birth } & Rural & 1917 & 369 & 457 & $2743(76.19 \%)$ \\
\hline & Urban & 533 & 231 & 93 & $857(23.81 \%)$ \\
\hline \multirow{3}{*}{$\begin{array}{l}\text { Parent's } \\
\text { education }\end{array}$} & No education & 543 & 71 & 177 & $791(21.97 \%)$ \\
\hline & $\begin{array}{l}\text { Primary/ } \\
\text { secondary level }\end{array}$ & 1274 & 143 & 154 & $1571(43.64 \%)$ \\
\hline & Higher level & 633 & 386 & 219 & $1238(34.39 \%)$ \\
\hline \multirow{3}{*}{$\begin{array}{l}\text { Economic } \\
\text { status }\end{array}$} & Higher & 522 & 288 & 129 & $1037(28.81 \%)$ \\
\hline & Middle & 1343 & 114 & 289 & $1746(48.5 \%)$ \\
\hline & Lower & 487 & 198 & 132 & $817(22.69 \%)$ \\
\hline \multirow{2}{*}{$\begin{array}{l}\text { Participant's } \\
\text { awareness } \\
\text { about vaccine }\end{array}$} & Aware & 694 & 414 & 367 & $1475(40.97 \%)$ \\
\hline & Not aware & 1756 & 186 & 183 & $2125(59.03 \%)$ \\
\hline
\end{tabular}

Table II illustrates the rate of receiving different vaccines among participants. Out of 3600 study population for bacterial vaccine, rate of Tetanus vaccine was highest in percentage which was 1248 (34.67\%). Percentage of other bacterial vaccines like Cholera and ETEC diarrhea, Meningococcal, Pneumococcal and Typhoid vaccination percentages were only $27(0.75 \%), 29(0.81 \%), 111$ $(3.08 \%)$ and 34(0.94\%) respectively. Among viral vaccines, the highest receiving vaccine was Hepatitis B. $2763(76.75 \%)$ students were immune with hepatitis B vaccine. Percentage of Hepatitis A was 337 (9.36\%), Rota was 330 (9.17\%), Measles Mumps Rubella was 249
(6.92\%) and Chicken pox was 83(2.31\%). Percentage was below in case of Cervical HPV and Seasona flu vaccine which were $12(0.33 \%)$ and $20(0.56 \%)$ respectively.

Table -II: Vaccination schedule for recommended vaccines in study population $(n=3600)$ :

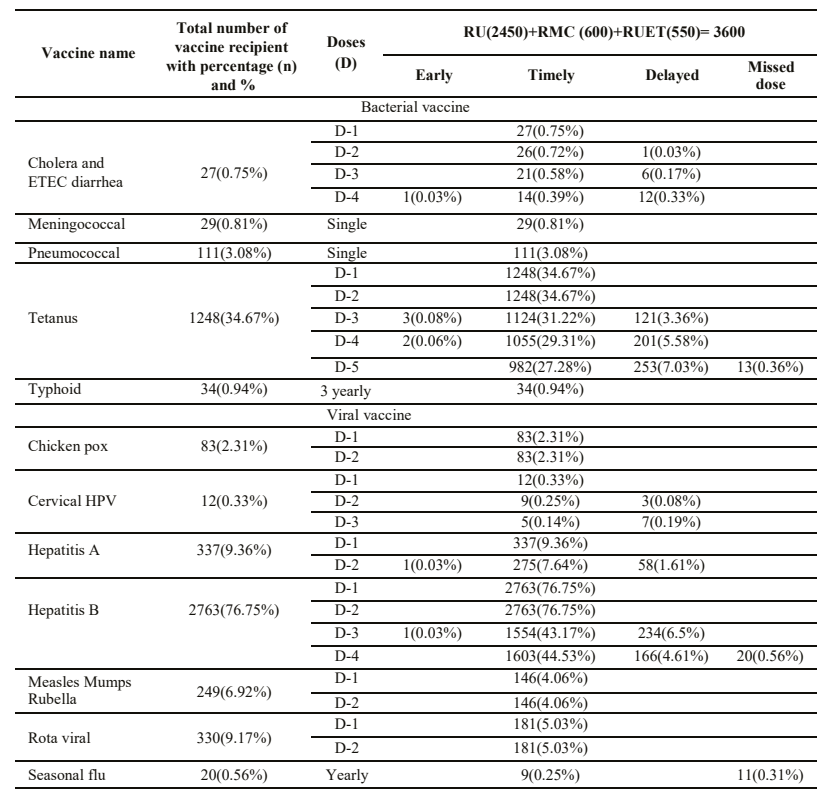

Out of total 3600 students, only $27(0.75 \%)$ students were vaccinated with Cholera and ETEC diarrhea vaccine whereas after receiving first dose, timely vaccination was performed in $26(0.72 \%), 21(0.58 \%)$ and $14(0.39 \%)$ in dose-2, dose- 3 and dose- 4 respectively, however, there was history of delayed vaccination in $1(0.03 \%), 6(0.17 \%)$ and $12(0.33 \%)$ in dose- 2 , dose- 3 and dose- 4 . At the same time in case of receiving dose- 4 early vaccine was performed in $1(0.03 \%)$ student. Single-dose-bacterial-vaccine; Meningococcal and Pneumococcal were taken by $29(0.81 \%)$ and $111(3.08 \%)$ participants respectively. At the same time every 3-year-Typhoid-vaccine was received by 34 (0.94\%) participants. In case of Tetanus vaccine the proportion students who had received 1st dose of vaccination was 1248 (34.67\%). Timely vaccination rate was $1248(34.67 \%)$, $1124(31.22 \%), 1055(29.31 \%)$ and 982 (27.28\%) population in $2 \mathrm{nd}, 3 \mathrm{rd}$, 4th and 5th dose respectively. However there was history of $121(3.36 \%), 201(5.58 \%)$ and 253 $(7.03 \%)$ delayed vaccination in 3rd, 4th and 5th doses respectively. Just as early vaccination was also reported 3 $(0.08 \%)$ in 3 rd dose and $2(0.06 \%)$ in 4 th dose vaccination. In case of 5th dose about $13(0.36 \%)$ participant failed to receive their scheduled vaccines. Viral-vaccine; Chicken pox had received by $83(2.31 \%)$ participant and all took their 2nd dose of vaccine timely. Similarly Measles Mumps Rubella vaccine had taken by $146(4.06 \%)$ population and following dose was also received at the schedule time by all. Three-dose- Cervical HPV vaccine recipient rate was only $12(0.33 \%)$. Second dose had taken timely by 9 $(0.25 \%)$ and delayed rate was $3(0.08 \%)$. Third dose was received in the schedule date by $5(0.14 \%)$ participant however delayed by $7(0.19 \%)$ students. 
About 337 (9.36\%) of all students were received 1st dose of Hepatitis A vaccine. During the second dose schedule time early recipient rate was $1(0.03 \%)$, timely recipient rate was $275(7.64 \%)$ and delayed recipient rate was $58(1.61 \%)$. The highest received vaccine was Hepatitis B. Approximately 2763(76.75\%) students had history of hepatitis $\mathrm{B}$ vaccination. Following dose was taken in the schedule date by all participants. At the time of dose, three $1(0.03 \%)$ had early vaccination history, 1554 (43.17\%) took timely and $234(6.5 \%)$ received delayed vaccine. Fourth dose timely recipient rate was 1603 (44.53\%) whereas 166 (4.61\%) had delayed vaccination and about 20 $(0.56 \%)$ failed to receive the scheduled vaccine.

Two-dose-Rota-vaccine was received by $181(9.17 \%)$ participant in their schedule time. Seasonal flu vaccine was received by $20(0.56 \%)$ participant, out of that only 9 $(0.25 \%)$ continued their yearly vaccination nonetheless 11 $(0.31 \%)$ didn't continue this yearly vaccine as schedule.

\section{Discussion:}

Vaccination is the most effective interventions for preventing and lowering the burden of disease. Nonetheless, faulty and incomplete vaccination is a crucial problem for our country.

A number of factors were associated with the failure of the vaccination schedule in this study. Parents' education, economic status and awareness about vaccine were the most significant influencing factors. In this study, parents' education was significantly associated with the failure of timely vaccination. Who had no formal education, had completed a primary or secondary level of education were more likely to have failed to receive multi-dose vaccines as compared with who had completed a higher level of education. Similar patterns have been observed; parents with a lower educational level ${ }^{8,9,10}$ were less likely to utilize immunization services ${ }^{11,12,13}$.

Our results demonstrated that the financial status acted as an influencing factor for the failure of timely multi-dose vaccines (Cholera and ETEC diarrhea, cervical HPV, hepatitis A, hepatitis B), however, such failures were not observed in single-dose vaccines such as Meningococcal and pneumococcal vaccine. Similarly, more expensive vaccines like diarrhea, meningococcal, pneumococcal, typhoid, cervical HPV, Rota and seasonal flu vaccines were significantly more likely to be at higher risk of failing to receive. Only $0.75 \%, 0.81 \%, 3.08 \% 0.94 \%, 0.33 \%, 9.17 \%$ and $0.56 \%$ people had history of receiving those vaccines respectively. However, such relationship was not observed in tetanus vaccine which is a low cost vaccine.

It was observed that $0.36 \%, 0.56 \%$ and $0.31 \%$ didn't complete their vaccination schedule for Tetanus, Hepatitis $\mathrm{B}$ and seasonal flu vaccine respectively. Awareness about vaccine and diseases were another critical issue for utilization of vaccination services. Who was not aware about the relationship between vaccine and diseases were significantly more likely to have failed to receive multi-dose vaccines.

In case of multi-dose-vaccines, early vaccination was noted for Cholera and ETEC diarrhea, Tetanus, Hepatitis A and Hepatitis B. Delayed vaccination was reported for most of the multi dose vaccines. Early vaccination may cause failure to produce proper protective antibody response against diseases 14,15,16. Whereas delayed 17, 18 and missed vaccination takes longer and inappropriate production of antibody 19, 20,21. Although small percentage of people received early vaccine than delayed vaccine however both are considered as inappropriate.

\section{Conclusion:}

Although Expanded Programme of Immunization (EPI) is one of the most vital and successful interventions of government in Bangladesh, and contributing significantly to reduce mortality and morbidity from vaccine preventable diseases, however, people are still not aware of other non EPI bacterial and viral vaccines which can protect people from life threatening diseases and their complications. Increasing of peoples' awareness of vaccines should increase the rate of vaccine-coverage and protect people from unusual health hazards.

\section{Conflict of Interest: None.}

\section{Acknowledgement:}

We are thankful to all staffs of Rajshahi University, Rajshahi Medical College and Rajshahi University of Engineering and Technology for their cooperation.

\section{References:}

1. Keja, K., Chan, C. Hayden, G. Henderson, R. Expanded programme on immunisation. World Health Stat. Q.1988;41:59-63.

2. Anderson, R. M. \& May, R. M. Infectious Diseases of Humans. 3rd Ed.Oxford: Oxford University Press;1991.

3. Barata, R.B.; Ribeiro, M.C.S.D.A.; De Moraes, J.C.; Flannery, B. Socioeconomic inequalities and vaccination coverage: Results of an immunisation coverage survey in 27 Brazilian capitals. 2007-2008. J. Epidemiol. Commun. Health. 2012; 66: 934-941.

https://doi.org/10.1136/jech-2011-200341

PMid:22268129 PMCid:PMC3433223

4. Andre, F.E., Booy, R., Bock, H.L., et al. vaccination greatly reduces disease, disability, death and inequity worldwide. Bull. World Health Organ.2008;86:140-146.

https://doi.org/10.2471/BLT.07.040089

\section{PMid:18297169 PMCid:PMC2647387}

5. World Health Organization (WHO). Immunisation Surveillance, Assessment and Monitoring; World Health Organization: Washington, DC, USA; 2014.

6. Chowdhury, M.R., Bhuiya, A., Simeen Mahmud, S., et al. Immunisation Divide: Who Do Get Vaccinated in 
Bangladesh?. J. Health, Population and Nutrition. 2003; 21:193-204.

7. Black, R.E., Cousens, S., Johnson, H.L, et al. Global, regional, and national causes of child mortality in 2008: A systematic analysis.Lancet. 2010;375:1969-1987.

https://doi.org/10.1016/S0140-6736(10)60549-1

8. Contreras, G. Effect of the administration of oral poliovirus vaccine on infantile diarrhoea mortality. Vaccine. 1989; 7: 211-2.

https://doi.org/10.1016/0264-410X(89)90230-2

9. Fonseca, W., Kirkwood, B.R., Victora, C.G., et al. Risk factors for childhood pneumonia among the urban poor in Fortaleza, Brazil: a case-control study. Bull. World Health Organization. 1996;74: 199-208.

10. Ghendon Y.Z., Kaira A.N. and Elshina G.A. The effect of mass immunisation in children on the morbidity of the unvaccinated elderly. Epidemiol. Infect. 134: 71-78.

https://doi.org/10.1017/S0950268805005650

PMid:16316494 PMCid:PMC2870375

11. Oyefara, J.L. Mothers' Characteristics and immunisation status of under-five children in Ojo Local Government Area, Lagos State, Nigeria. SAGE Open. $2014 ; 4$.

https://doi.org/10.1177/2158244014545474

12. Heininger, U., Zuberbühler, M. Immunization rates and timely administration in pre-school and school-age children. Eur. J. Pediatr.2006;165:124-129.

https://doi.org/10.1007/s00431-005-0014-y

PMid:16328365

13. Jamil, K. The immunisation programme in Bangladesh: impressive gains in coverage, but gaps remain. Health Policy and Planning. 1999; 14: 49-58.

https://doi.org/10.1093/heapol/14.1.49

PMid:10351469

14. Fadnes, L.T., Jackson, D., Engebretsen, I.M. The PROMISE-EBF Study Group. Vaccination coverage and timeliness in three South African areas:A prospective study. BMC Public Health.2011;11:404.

https://doi.org/10.1186/1471-2458-11-404

PMid:21619642 PMCid:PMC3126743
15. Koenig, M.A., Bishai, D. and Khan, M.A. Health interventions and health equity: the example of measles vaccination in Bangladesh. Popul. Dev. Rev. 2001; 27: 283-302.

https://doi.org/10.1111/j.1728-4457.2001.00283.x

16. Oyefara, J.L. Mothers' Characteristics and immunisation status of under-five children in Ojo Local Government Area, Lagos State, Nigeria. SAGE Open. 2014: 4.

https://doi.org/10.1177/2158244014545474

17. Zaidi, S.M.A., Khowaja, S., Dharma, V.K., et al. Coverage, timeliness, and determinant sof immunisation completion in Pakistan: Evidence from the Demographic and Health Survey (2006-07). Hum. Vaccines Immunother.2014;10:1712-1720.

https://doi.org/10.4161/hv.28621

\section{PMid:24784118 PMCid:PMC5396236}

18. Perz J.F., Elm J.L., Fiore A.E., Huggler J.I., Kuhnert W.L. and Effler P.V. Near elimination of hepatitis B virus infections among Hawaii elementary school children after universal infant hepatitis B vaccination. Pediatr. Ics. 2006; 118: $1403-1408$.

https://doi.org/10.1542/peds.2006-0724

PMid: 17015529

19. Heininger, U., Zuberbühler, M. Immunization rates and timely administration in pre-school and school-age children. Eur. J. Pediatr.2006;165:124-129.

https://doi.org/10.1007/s00431-005-0014-y

\section{PMid: 16328365}

20. Silva, D.R., Herm, Khan, H.M. and Chowdhury, JH. Bangladesh national immunisation cluster survey. In: Huq M, editor. Near miracle in Bangladesh. Dhaka: University Press Ltd., 1991: 85-96.

21. Uddin, M.J.; Adhikary, G.; Ali, M.W.; Ahmed, S.; Shamsuzzaman, M.; Odell, et al. Evaluation of impact of measles rubella campaign on vaccination coverage and routine immunisation services in Bangladesh. BMC Infect. Dis. 2016; 16: 411.

https://doi.org/10.1186/s12879-016-1758-x

PMid:27519586 PMCid:PMC4983043 